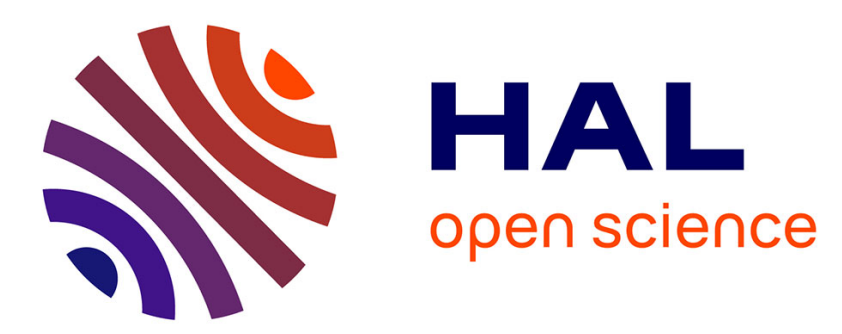

\title{
A Novel Sizing Environment (DSP-1) Dealing With Semi-Numerical Models Applied to the Optimization of a Bi-Stable Out-of-Plane Magnetic Micro-Switch
}

Hichem Chetouani, Hervé Rostaing, Frédéric Wurtz, Gilbert Reyne, Benoît Delinchant

\section{To cite this version:}

Hichem Chetouani, Hervé Rostaing, Frédéric Wurtz, Gilbert Reyne, Benoît Delinchant. A Novel Sizing Environment (DSP-1) Dealing With Semi-Numerical Models Applied to the Optimization of a Bi-Stable Out-of-Plane Magnetic Micro-Switch. IEEE Transactions on Magnetics, 2006, 42 (4), pp 1231- 1234. hal-00335366

\section{HAL Id: hal-00335366 https://hal.science/hal-00335366}

Submitted on 29 Oct 2008

HAL is a multi-disciplinary open access archive for the deposit and dissemination of scientific research documents, whether they are published or not. The documents may come from teaching and research institutions in France or abroad, or from public or private research centers.
L'archive ouverte pluridisciplinaire HAL, est destinée au dépôt et à la diffusion de documents scientifiques de niveau recherche, publiés ou non, émanant des établissements d'enseignement et de recherche français ou étrangers, des laboratoires publics ou privés. 


\title{
A Novel Sizing Environment (DSP-1) Dealing With Semi-Numerical Models Applied to the Optimization of a Bi-Stable Out-of-Plane Magnetic Micro-Switch
}

\author{
H. Chetouani, H. Rostaing, F. Wurtz, G. Reyne, and B. Delinchant \\ Laboratoire d'Electrotechnique de Grenoble (LEG), ENSIEG, Domaine Universitaire, (UMR 5529 INPG/UJF-CNRS), BP 46, \\ F-38402 Saint Martin d'Hères, France
}

\begin{abstract}
The use of a semi-numerical model in order to optimize a magnetic micro-switch is proposed. It relies on a flexible sizing environment for which novel models based on sums, surface, and volume integrals necessary to express magnetic phenomena have been developed. Then, corresponding software components have been generated. This environment is applied to optimize a bi-stable out-of-plane magnetic micro-switch. The optimized micro-switch is dedicated to be used in optical micro-scanner application. Its main characteristics are high displacement (in excess of $100 \mu \mathrm{m})$, low switching time, and current consumption (300 mA). Results demonstrate a performing and generic way for fast design by optimization.
\end{abstract}

Index Terms-Magnetic microsystems and actuators, optimization, software components.

\section{INTRODUCTION}

$\mathbf{T}$ HE evolution of power microelectromechanical systems (MEMS), of micro-actuators and, more particularly, of systems based on magnetic actuation, has generated an increasing need for specific methodologies and tools adapted to their specific topology, where materials as micro-magnets, are gradually being integrated [1], [2]. Design of magnetic micro-systems often results in choosing between several possible structures. The multi-disciplinary optimization (MDO) [3] is one of the well-known alternatives used in various fields of design, to answer that problem. Though it remains until now not adopted in the field of magnetic micro-actuators. These multiphysical systems are generally modeled semi-numerically (typically by numerical integrals of analytical functions). That has resulted in the development of methods, tools, and environments [4] to cope with the whole design process. Several approaches exist in the literature for the expression of the magnetic phenomena. One is a volume segmentation approach [5]. Another one, which is more flexible, is semi-numerical and based on surface method simplification [6].

The optimization is one of the most important design steps. Today, to satisfy precise specifications of systems from diverse disciplines and topologies, the optimization of systems under constraints is frequently used. At first, a model representing the system is established. Then a specific corresponding software component [4] is generated and incorporated into an optimization environment (Fig. 1) including a determinist optimizer algorithm SQP (sequential quadratic programming) [7]. Iterations between these steps are generally necessary to reach a satisfactory solution.

The software component (Fig. 1) needs the value of the inputs (Ei) and their differential (dEi) in order to compute the outputs $(\mathrm{Sj})$ and their corresponding gradients $(\mathrm{dSj})$. Gradients computation is the most essential step in our optimization chain based on SQP optimization algorithm. Indeed, this calculation must

Digital Object Identifier 10.1109/TMAG.2006.871968

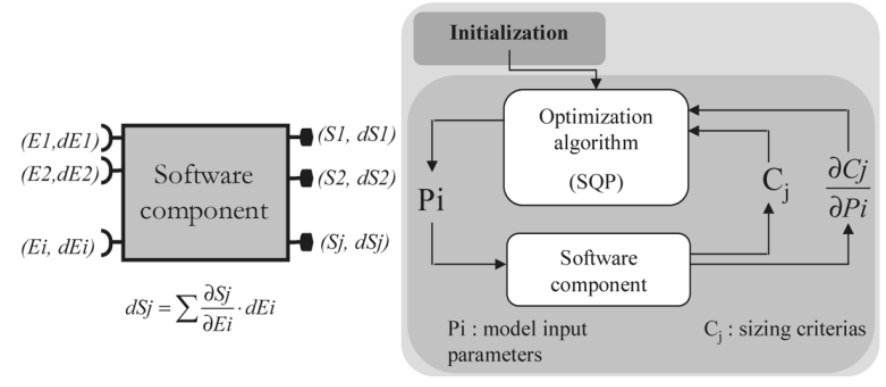

Fig. 1. Optimization under constrains using software components.

be sufficiently precise and fast enough. If the computation of the gradients is not precise enough, the system may not converge with solution satisfying the schedule of conditions. Thus, this calculation is very significant.

\section{ENVIRONMENT}

\section{A. Software Components Generation}

A determinist gradient-based optimization algorithm like VF13 [8] requires software components that should execute themselves independently and to deliver both sizing criteria and their differentials. These recommendations are the main specification of the generation process. The generation step consists on the construction of data processing files that contain the model computation code as well as the computation of differentials. This tool integrates a formal treatment component configured by an XML [9] file. It describes the necessary rules to build the symbolic differentials code of the mathematical expressions. Then, an integrated Java compiler compiles these files and then packages them automatically into a single autonomous file.

\section{B. Computation of Differentials Integrals and Sums}

Frequently, integrals and sums intervene at the models of magnetic micro-actuators and systems. These mathematical expressions are necessary to express magnetic fields, forces, 
torques, etc. The micro-switch model implements the surface method simplification to compute the total force of the fixed magnets on the mobile one. The same method is used to compute the magnetic field of the mobile magnet. Thus allowing computing Lorenz's force given by

$$
d F=i \cdot d l \wedge B
$$

where $d F$ is the Lorenz's force obtained from a $d l$ segment of the conductor, $i$ is the current intensity, $B$ is the magnetic induction field, and $d l$ is a segment length of the conductor. The force due to volume of the conductors is obtained by integration over the whole volume of conductors.

To build the formal differentials of the sizing criteria compared to the system inputs required by a gradient-based optimization algorithm, the differential of the mathematical expressions and functions are required. The formal differentials computation of these specific mathematical expressions requires a particular treatment. Examples of differentials computation of a simple integral and a sum are described respectively in example (1) and example (2). The integrals differentials computation is formally exact. Thus, the semi-numerical nature comes just from the numerical method used to compute the value of simple integrals intervening at their differentials computation.

Example 1:

$$
\begin{aligned}
& E(d, c, h)=\int_{a(d, h)}^{b(d, h)} Z(d, c, h, t) . d t \\
& \frac{\partial E(d, c, h)}{\partial c}=\int_{a(d, h)}^{b(d, h)} \frac{\partial Z(d, c, h, t)}{\partial c} \cdot d t \\
& \frac{\partial E(d, c, h)}{\partial h}=\left(\frac{\partial b(d, h)}{\partial h}-\frac{\partial a(d, h)}{\partial h}\right) \\
& \quad Z(d, c, h, a(d, h)) \\
& \frac{\partial E(d, c, h)}{\partial d}=\int_{a(d, h)}^{b(d, h)} \frac{\partial Z(d, c, h, t)}{\partial d} \cdot d t \\
& \quad+\left(\frac{\partial b(d, h)}{\partial d} \cdot-\frac{\partial a(d, h)}{\partial d}\right) \cdot Z(d, c, h, a(d, h)) \\
& \operatorname{grad}(E(d, c, h))=\frac{\partial E(d, c, h)}{\partial d} \cdot d d+\frac{\partial E(d, c, h)}{\partial c} \cdot d c \\
& \quad+\frac{\partial E(d, c, h)}{\partial h} \cdot d h
\end{aligned}
$$

Example 2:

$$
\begin{aligned}
& \operatorname{Sum}(x 1, \ldots, x i)=\sum_{n=1}^{10} f(n, x 1, \ldots, x i) \\
& \frac{\partial \operatorname{Sum}(x 1, \ldots, x i)}{\partial x 1}=\sum_{n=1}^{10} \frac{\partial f(n, x 1, \ldots, x i)}{\partial x 1} \\
& \vdots \\
& \frac{\partial \operatorname{Sum}(x 1, \ldots, x i)}{\partial x i}=\sum_{n=1}^{10} \frac{\partial f(n, x 1, \ldots, x i)}{\partial x i} \\
& \operatorname{grad}(\operatorname{Sum}(x 1, \ldots, x i)) \\
& =\sum_{i}^{1} \sum_{n=1}^{10} \frac{\partial \operatorname{Sum}(n, x 1, \ldots, x i)}{\partial x i} . d x i .
\end{aligned}
$$

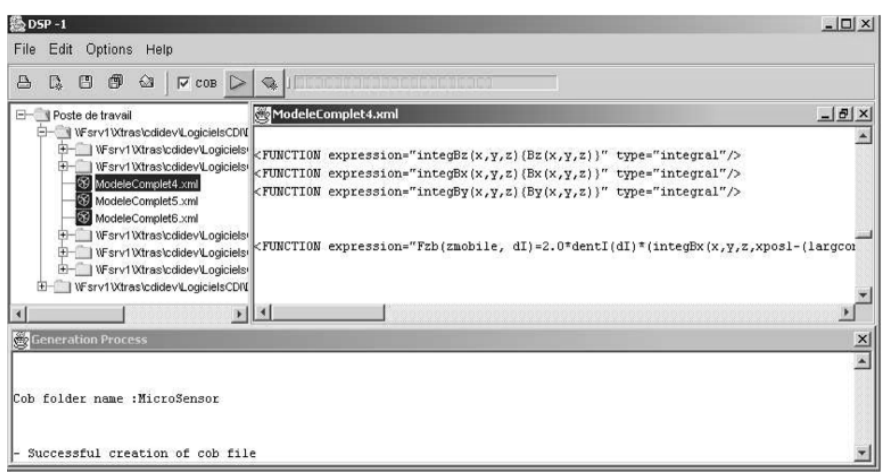

Fig. 2. Interface screenshot.

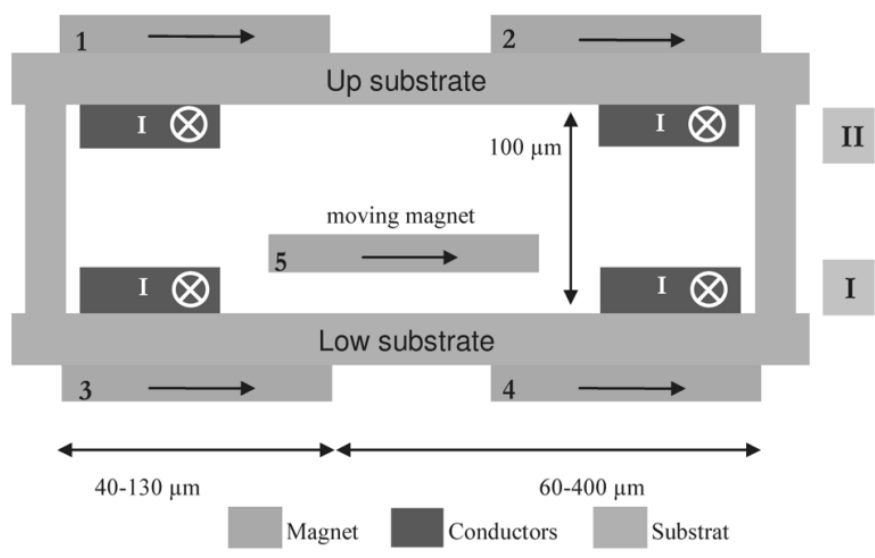

Fig. 3. Micro-switch structure.

DSP- 1 (Fig. 2) has been developed, in order to generate software component from models including (simple, double, and triple) integrals and sums.

\section{APPLICATION}

\section{A. Micro-Switch Structure}

The system (Fig. 3) is achieved by stacking two Silicon wafers onto which the planar magnets and the planar coils are deposited in superimposed layers. Principally, the micro-switch includes two symmetrical pairs of conductors which are designed in the high and low substrates, and five magnets based electroplated $\mathrm{CoPt}$ [10], which has a remanence induction of $0.5 \mathrm{~T}$ and a coercivity of $0.2 \mathrm{~T}$. Four magnets are fixed (numbered 1, 2, 3, and 4 on Fig. 3), and the fifth one is mobile (numbered 5).

The actuation of the mobile is generated by the total force plotted on (Fig. 4). Its results from the sum of: magnetic force exerted by the whole fixed magnets, and the Lorenz's force exerted by the two pairs of conductors (since the structure contains no iron, superposition law is authorized).

\section{B. Actuation Principle}

The mobile magnet (Fig. 3) moves freely between two states: up state (I) and down state (II), and maintained in high and down stable positions respectively by the fixed magnets (1-2) and (3-4). During switching, the mobile magnet is neither guided nor maintained by any mechanical elements. The fixed magnets 


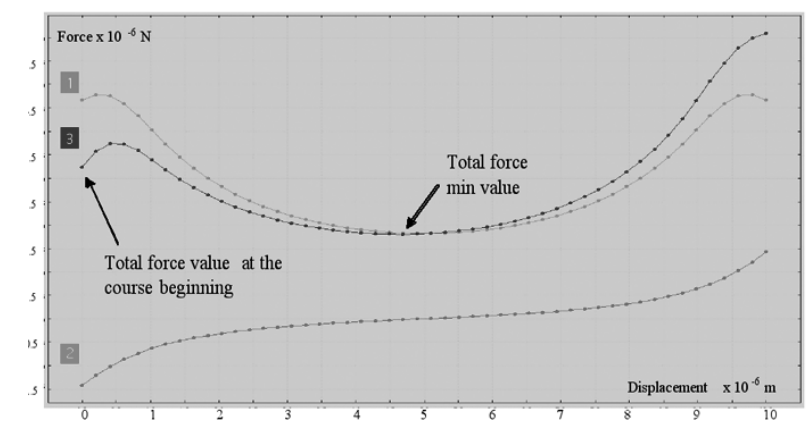

Fig. 4. Forces on the moving magnet. (Curve 1) Force due to the two pairs of conductors on the moving magnet. (Curve 2) Force due to the fixed magnets on the moving magnet. (Curve 3 ) Total force on the mobile magnet which equals to $(1)+(2)$.
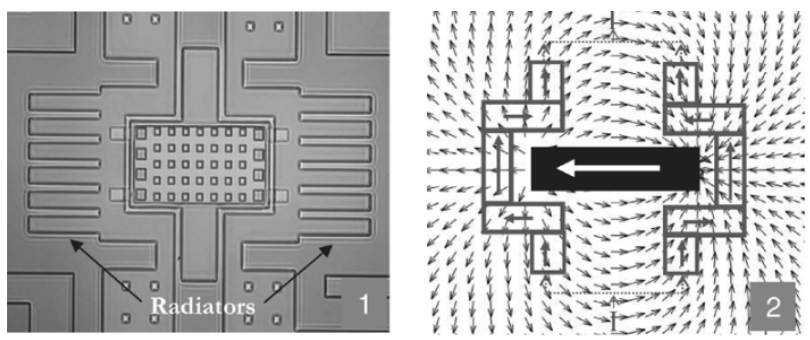

Fig. 5. (1) Radiators implanting in the substrate and coupled to the conductors on the down substrate. (2) Cartography of the magnetic field generated by the mobile magnet, and location of the conductors.

allow the free magnet to be centered at the medium of the horizontal plane during the whole displacement including its two stable positions. A current pulse injected within the conductors acts on the mobile magnet causing its displacement from a stable position to another one. The use of current pulses of $500 \mu \mathrm{s}$ permits high current density $\left(>10 \mathrm{kA} / \mathrm{mm}^{2}\right)$, and gives the necessary time to the conductors coupled to radiators to evacuate the heating into the substrate (Fig. 5). A high density of current provokes thermal problems [12], [13], but allows to have a bigger force, a higher speed, and longer switching. The interaction between currents and magnets are among the most efficient at small scales [11], and can become very interesting if high-current densities are used. Due to the action-reaction law, one can either analyze the magnetic force of conductors on the magnets or, the Lorenz's force exerted onto the conductors by the magnetic field of the mobile magnet. Fig. 5 illustrates an up view of the magnetic field generated by the mobile magnet. Conductors are located around the magnet tips, so that currents and magnetic field are perpendicular to each other.

\section{Micro-Switch Specifications}

Magnets are gradually being integrated in the world of micro-actuators and power MEMS. The micro-actuators based on magnets benefit from the macro version by the advantages of the scale decrease (Increase of mass force, and price reduction, etc.), and the inconvenient (limitation in materials choice, difficulty of having great thickness for some materials as CoPt, thermal dissipation, etc.). To cope with the constraints of the small world, two different optimizations have been achieved corresponding to the choice of different criteria to optimize. The first specification has as optimization criteria the current intensity into the conductors. Meanwhile, the force has been constrained both at the beginning and at the middle of the displacement, respectively $>1 \mu \mathrm{N}$, and $>0.5 \mu \mathrm{N}$. The second specification is the opposite. The force is now considered as the optimization criteria, while the current intensity and density have been constrained to be respectively less than $0.6 \mathrm{~A}$, and $30000 \mathrm{~A} / \mathrm{mm}^{2}$. Both specifications share other common constraints related to the physics and the micro technology as:

- magnets' geometrical parameters: the size of the magnets may admit changes which respect a minimal form factor: length/width above 1.5, so they are not subject to demagnetization;

- maximal magnet height of $5 \mu \mathrm{m}$ is allowed, related to the resins thickness used for the electrolyze deposition of $\mathrm{CoPt}$;

- a resistance against shocks and vibrations above $15 \mathrm{~g}$ $\left(\mathrm{g}=9.81 \mathrm{~m} / \mathrm{s}^{2}\right)$, which is computed by the latching force applied on the mobile magnet at a stable state compared to its mass;

— the mobile magnet course is fixed to be $100 \mu \mathrm{m}$;

— the whole system area must be $<2 \mathrm{~mm}^{2}$;

- geometrical constraints on the conductors' size;

- constraints on the gaps between the mobile and the fixed magnets, and others conductors/conductors type.

\section{Minimum of the Force Management}

When the minimum of the force is constrained to a value greater than $0.5 \mu \mathrm{N}$, the difficulty is to know where this minimum is. Indeed, this minimum position varies along the displacement with each iteration. This poses a problem to complete the optimization process. The use of an specific algorithm encapsulated inside the model to calculate the minimal value of the force for every iteration established by the optimization algorithm VF13, has appeared ominous in terms of time cost. The introduction of a new constraint to the specifications has been adopted as an alternative. It considers that force is minimal at the middle of the displacement course. Therefore, the force is directly constrained at this position. The approximation adopted does not affect the results, since physically this minimal value is not far from this point.

\section{RESULTS}

Results of the optimization obtained by the two specifications are good. In both cases, a greater force with less current consumption is obtained (Table I). These results correspond respectively to a current optimum and a force optimum. The total force on the mobile magnet along the displacement at the force optimum case and current optimum case are illustrated in Fig. 6.

The two solutions illustrated in Fig. 6 are the optimums of the two applied specifications. These two solutions can provide different orientations in term of application (optical micro-scanner [15]). Geometries resulting from the two solutions reveal some interesting information. For the current optimum (Fig. 7), the conductors are thicker and their geometry has changed at the corners of mobile magnet, where the parts which are horizontal to the magnetization direction became shorter, to increase the Lorenz's force. 
TABLE I

CURRENTS AND Forces VALUES BEFore AND AFter the Optimization

\begin{tabular}{|c|c|c|c|}
\cline { 2 - 4 } \multicolumn{1}{c|}{} & $\begin{array}{c}\text { Current } \\
\text { intensity }\end{array}$ & $\begin{array}{c}\text { Force value at } \\
\text { the beginning of } \\
\text { the switching }\end{array}$ & $\begin{array}{c}\text { Force min } \\
\text { value along } \\
\text { the switching }\end{array}$ \\
\hline $\begin{array}{c}\text { Values required by the } \\
\text { specifications }\end{array}$ & $<\mathbf{0 . 7 \mathrm { A }}$ & $>\mathbf{1} \boldsymbol{\mu N}$ & $>\mathbf{0 . 5} \boldsymbol{\mu N}$ \\
\hline Before optimization & $\mathbf{3 . 7 \mathrm { A }}$ & $\mathbf{1} \boldsymbol{\mu \mathrm { N }}$ & $\mathbf{1 . 5} \boldsymbol{\mu \mathrm { N }}$ \\
\hline $\begin{array}{c}\text { After optimization } \\
\text { (1) for force optimum }\end{array}$ & $\begin{array}{c}\mathbf{0 . 6 \mathrm { A }} \\
-84 \%\end{array}$ & $\begin{array}{c}\mathbf{6 . 5} \boldsymbol{\mu N} \\
+550 \%\end{array}$ & $\begin{array}{c}\mathbf{4 . 2} \boldsymbol{\mu N} \\
+180 \%\end{array}$ \\
\hline $\begin{array}{c}\text { After optimization } \\
\text { (2) for current optimum }\end{array}$ & $\begin{array}{c}\mathbf{0 . 3} \mathrm{A} \\
-92 \%\end{array}$ & $\begin{array}{c}\mathbf{1 . 5} \boldsymbol{\mu N} \\
+50 \%\end{array}$ & $\begin{array}{c}\mathbf{1 . 8} \boldsymbol{\mu N} \\
+12 \%\end{array}$ \\
\hline
\end{tabular}
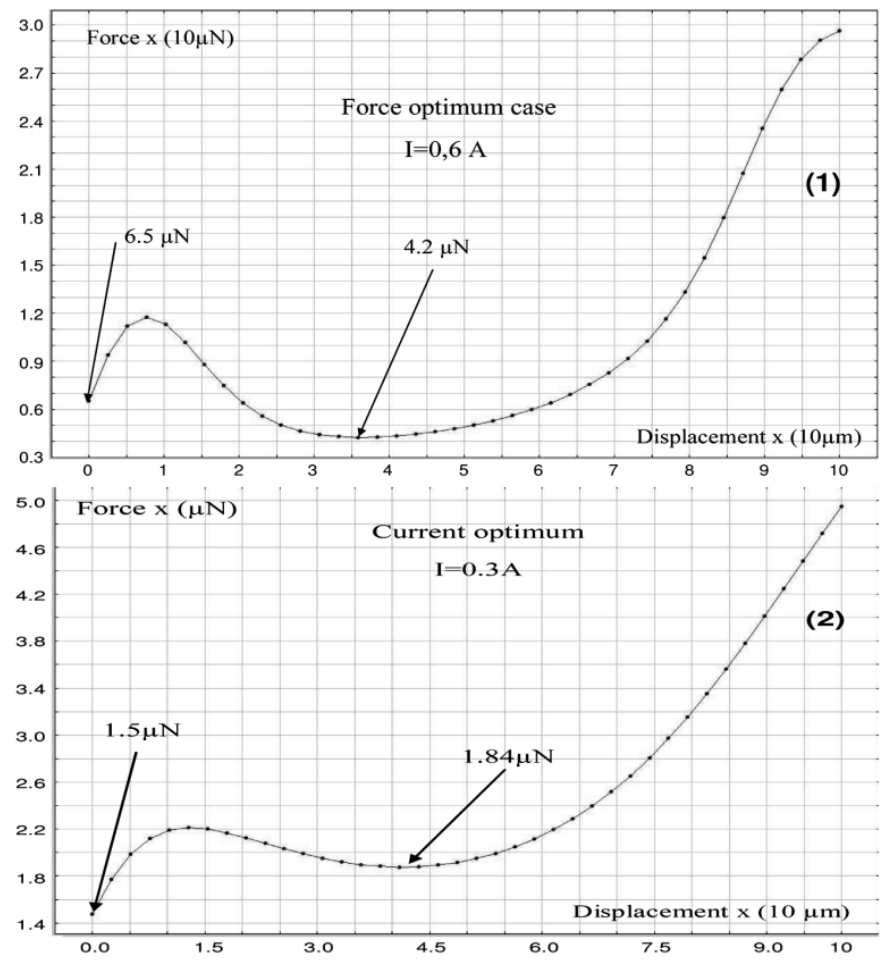

Fig. 6. Total force on the mobile magnet during the switching length. (1) The force optimum case ( $\mathrm{I}=0.6 \mathrm{~A})$. (2) The current optimum case ( $\mathrm{I}=0.3 \mathrm{~A}$ ).

\section{CONCLUSION}

A novel-sizing environment including new functionalities and treatment capacities has been reported. This generic environment is dedicated to generate components from models containing integrals and/or discrete sums expressions. It provides good, efficient, and rapid optimization results. It prevents the designers from using some heavy numerical methods such as the finite elements (FEM). This is confirmed by the use of the semi-numerical approach and DSP-1 environment on the micro-switch optimization.
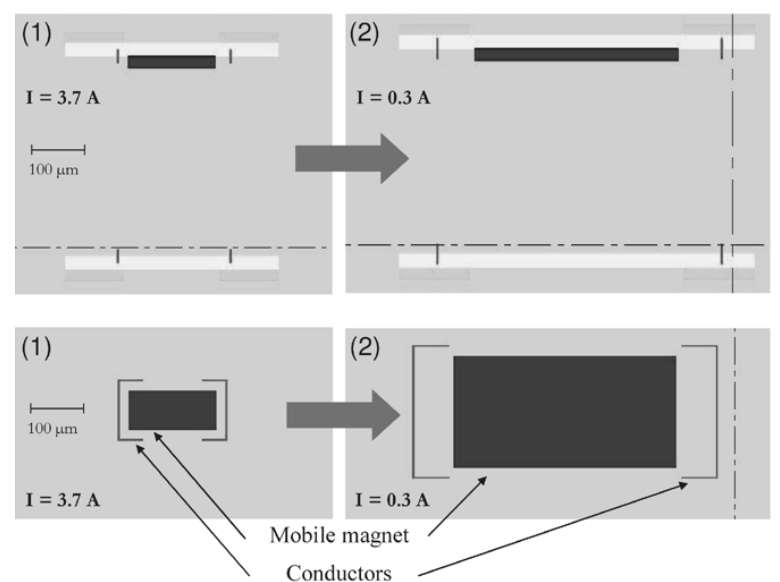

Fig. 7. Micro-switch geometry. (1) Initial geometry. (2) Final geometry after the optimization corresponding to the current optimum.

\section{REFERENCES}

[1] J. C. Hyoung and C. H. Ahn, "A bidirectional magnetic microactuator using electroplated permanent magnet array," J. Microelectromechanical Syst., vol. 1, no. 1, Feb. 2002.

[2] J. Stepanek, H. Rostaing, J. Delamare, and O. Cugat, "Fast dynamic modeling of magnetic microactuator," in ICM 2003, Roma (Italy), Jul. 27-Aug. 1, 2003. (JMM 2004) ICM'03, vol. 272-276P1, Rome, Jul. 2003, pp. 669-671.

[3] B. Delinchant, F. Wurtz, and E. Atienza, "Reducing sensitivity analysis time-cost of compound model," IEEE Trans. Magn., vol. 40, no. 2, pp. 1216-1219, Mar. 2004.

[4] B. Delinchant, "Un Environnement à base de Composants, Intégrant le Concepteur et ces Outils, pour de Nouvelles Méthodes de CAO," Thèse INPG, spécialité Génie Electrique, 2003.

[5] J. Delamare, E. Rulliere, and J. P. Yonnet, "3D calculation of permanent magnet interaction," in IMACS TC'1, Canada, 1993, pp. 289-292.

[6] G. Akoun and J. P. Yonnet, "3D analytical calculation of the forces exerted between two cubiodal magnets," IEEE Trans. Magn., vol. MAG-20, no. 5, pp. 1962-1964, Sep. 1984.

[7] C. Singh and D. Sarkar, "Practical considerations in the optimization of induction motor design," IEE Proc.-B, vol. 139, no. 4, pp. 365-373, Jul. 1992.

[8] VF13 [Online]. Available: http://www.cse.clrc.ac.uk/nag/hsl/

[9] XML [Online]. Available: http://www.xml.com

[10] D. Gamet, "Elaboration par voie électrochimique, caractérization et intégration pour application industrielles, d'aimants permanent à base de Co-Pt," Thèse de doctorat de Université Joseph Fourier, 2003.

[11] J. Delamare, G. Reyne, and O. Cugat, "Ch. 2: Réduction d'échelle," in Micro-actionneurs électromagnétiques MAGMAS, H. Sciences-Lavoisier, Ed., Déc. 2002, p. 340. ISBN 2-7462-0449.

[12] O. Cugat, J. Delamare, and G. Reyne, "MAGnetic micro-actuators \& systems MAGMAS," IEEE Trans. Magn., vol. 39, no. 6, pp. 3608-3612, Nov. 2003.

[13] G. Reyne, J. Delamare, and O. Cugat, "Ch. 3: Densités de courant," in Micro-actionneurs électromagnétiques MAGMAS, H. Sciences-Lavoisier, Ed., Déc. 2002, p. 340. ISBN 2-7462-0449-5.

[14] Y. Takahashi and G. Reyne, "Magnetic actuated optical scanner," in 12th Symp. Electromagnetics and Dynamics Proc., Okinawa, Japan, Jun. 29, 2000, pp. 85-86.

Manuscript received June 25, 2005 (e-mail: hichem.chetouani@leg.ensieg. inpg.fr). 